\title{
Al-Pr-Sb (Aluminum-Praseodymium-Antimony)
}

\section{Raghavan}

Recently, an isothermal section at $500{ }^{\circ} \mathrm{C}$ for this ternary system was determined by [2008Zen]; this depicts a ternary compound of unknown structure.

\section{Binary Systems}

The Al-Pr phase diagram [Massalski2] shows the following intermediate compounds: $\alpha \mathrm{Pr}_{3} \mathrm{Al}\left(D 0_{19}, \mathrm{Ni}_{3} \mathrm{Sn}\right.$-type hexagonal), $\beta \mathrm{Pr}_{3} \mathrm{Al}\left(L 1_{2}, \mathrm{AuCu}_{3}\right.$-type cubic), $\mathrm{Pr}_{2} \mathrm{Al}$ (C23, $\mathrm{Co}_{2} \mathrm{Si}$-type orthorhombic), $\alpha \operatorname{PrAl}$ (ErAl-type orthorhombic), $\beta \operatorname{PrAl}$ (CeAl-type orthorhombic), $\operatorname{PrAl}_{2}\left(C 15, \mathrm{MgCu}_{2}\right.$-type cubic), $\mathrm{PrAl}_{3}\left(\mathrm{Ni}_{3} \mathrm{Sn}\right.$-type hexagonal), $\mathrm{PrAl}_{4}$ or $\mathrm{BPr}_{3} \mathrm{Al}_{11}$ (D1 $3, \mathrm{Al}_{4} \mathrm{Ba}$-type tetragonal), and $\alpha \mathrm{Pr}_{3} \mathrm{Al}_{11}\left(\alpha \mathrm{La}_{3} \mathrm{Al}_{11}\right.$-type orthorhombic). The Al-Sb phase diagram depicts the equiatomic compound $\mathrm{AlSb}$, which melts congruently at $1058{ }^{\circ} \mathrm{C}$ [Massalski2]. The Pr-Sb phase diagram [Massalski2] depicts the following compounds: $\mathrm{Pr}_{2} \mathrm{Sb}$ ( $\mathrm{La}_{2} \mathrm{Sb}$-type tetragonal), $\mathrm{Pr}_{5} \mathrm{Sb}_{3} \quad\left(\mathrm{Mn}_{5} \mathrm{Si}_{3}\right.$-type hexagonal), $\mathrm{Pr}_{4} \mathrm{Sb}_{3}$ $\left(\mathrm{Th}_{3} \mathrm{P}_{4}\right.$-type cubic), $\beta \mathrm{PrSb}$ (stable above $1950{ }^{\circ} \mathrm{C}$ ), $\alpha \mathrm{PrSb}$ (NaCl-type cubic), and $\mathrm{PrSb}_{2}$ ( $\mathrm{SmSb}_{2}$-type orthorhombic).

\section{Ternary Isothermal Section}

With starting metals of $99.9 \% \mathrm{Al}, 99.8 \% \mathrm{Pr}$, and $99.9 \% \mathrm{Sb}$, [2008Zen] arc-melted or induction-melted a total of 98 binary/ternary alloys. The alloys were given a final anneal at $500{ }^{\circ} \mathrm{C}$ for 10 days and quenched in liquid nitrogen. X-ray powder diffraction and scanning electron microscopy with energy dispersive analyzer were used to study the phase equilibria. The isothermal section constructed by [2000Zen] at $500{ }^{\circ} \mathrm{C}$ is redrawn in Fig. 1. A ternary compound $\sim \mathrm{Al}_{11} \operatorname{Pr}_{24} \mathrm{Sb}_{63}(\tau)$ of unknown structure was found.

\section{Reference}

2008Zen: L. Zeng, J. Liao, P. Qin, H. Qin, and L. Nong, Phase Relations in the Al-Pr-Sb System at $773 \mathrm{~K}$, J. Alloys Compd., 2008, 450, p 252-254

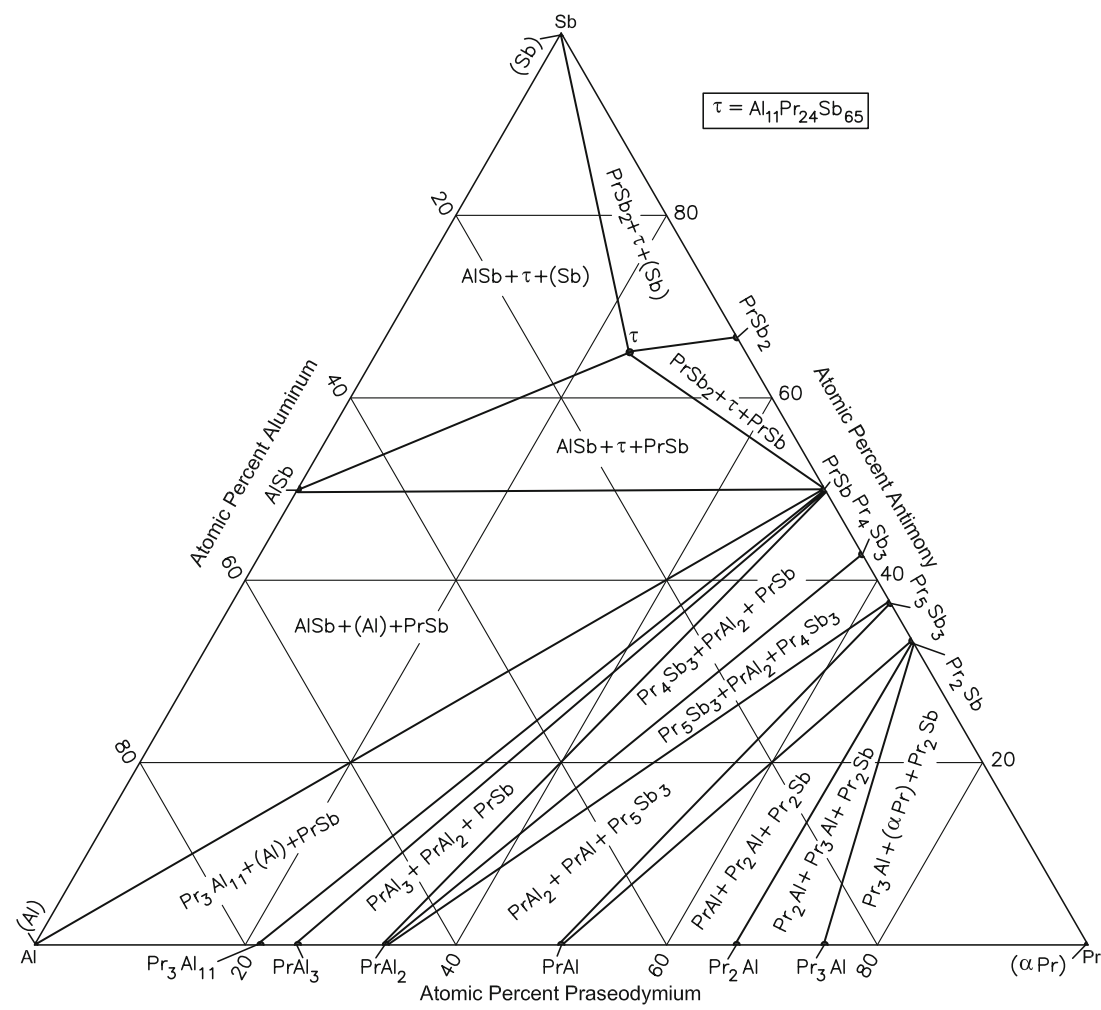

Fig. 1 Al-Pr-Sb isothermal section at $500{ }^{\circ} \mathrm{C}$ [2008Zen]. Two-phase regions are omitted 